\title{
The experiment research about grading teaching in college tennis —-In the case of Tianjin University Renai College
}

\author{
Yibao Tong ${ }^{1,}$ a , Zhenyu Qiu ${ }^{2, b}$ \\ ${ }^{1}$ School of Yibao Tong, Tianjin University Renai College, Tianjin 300000, China; \\ ${ }^{2}$ School of Zhenyu Qiu, Tianjin University Renai College, Tianjin 300000, China. \\ atongyibao1982@126.com, 'bongyibao1982@126.com
}

Keywords: College, tennis, PE, Grading teaching, Tianjin University Renai College.

\begin{abstract}
This thesis makes the theoretical and practical research about the design and application of the grade teaching mode in tennis optional course. According to the teaching principles in accordance with their aptitude and distinction, and combining the rules and characteristics about PE(physical education) teaching of students, the thesis presents the grade teaching mode which adopting the organization way of multi-level teaching according to the student's athletic ability and skill level in PE teaching and its specific embodiments. After analyzing the advantages of grace teaching, the teaching research shows the effect of this teaching form is very obvious, it improve teaching quality, establish a kind of confidence and interest in learning.
\end{abstract}

\section{The problem}

With the deepening of PE teaching reform in colleges, the research and discussion of PE teaching methods is becoming a very important element in the current reform. For now, the vast majority of colleges' PE teaching still commonly uses the conventional manner, methods and means. That is, first grade offer basic physical education, sophomore open optional course, while some schools began the learning of optional course from the first grade class. On the surface, the students have the freedom to choose projects and the teacher. However, there are varying differences among students of a special class in physical fitness, PE consciousness, athletic ability and the basic technology. It makes the phenomenon that some student "feel hungry" while some one "cannot finish" has become very serious, thereby directly affect the overall effectiveness of teaching. Therefore, according to the actual situation of the students in different levels and different types, to make sure that all types of students are on their starting point to learn, get the best learning effect and obtain the greatest benefits, this research and discussion of the teaching methods is a very important topic in the current reform of college PE. According to the teaching principles in accordance with their aptitude and distinction, combining with the years of PE reform and practice, and through the study design and practice of hierarchical teaching methods in the tennis teaching, this thesis attempts to find an effective teaching method to do a in-depth study for PE teaching reform and promoting tennis teaching. This is for your reference only.

\section{Research Objects and Methods}

\subsection{Research Objects}

In this paper, 120 students in 2015 tennis optional class from Tianjin University Renai College were invited to be the research objects. It was randomly selected from the entire group of 60 students divided into two classes as the experimental classes; the remaining 60 students are divided into two classes as the control classes. The basic conditions of experimental classes and the control classes were roughly same. Before the experiment, the basic conditions of these two kinds of classes have been texted. The results showed that the average level of the test indicators were very close between the experimental classes and the control classes. Base on the statistical test, the experimental classes and control classes showed no significant differences in the four test indicators, so the methods met with the requirements of statistical comparison. 


\subsection{Research Methods}

\subsubsection{Literature Method}

This paper consulted some pertinent data and books based on this study and got a more comprehensive understanding of the research status and cutting-edge dynamic of the subject areas, these studies and outcome provided a theoretical and methodological basis for this research..

\subsubsection{Educational Experimentation}

Hierarchical teaching methods for tennis which this paper designed conducted one semester of teaching experiment. It took the approach that the experimental classes and the control classes to contrast in the case of they all have the same teaching schedule. In the experimental classes, 60 students were taught according to the grading differences of their tennis basic level; while the control classes still adopt the traditional teaching form. After the end of study, experimental classes and control classes were mixed to texted and evaluated which adopted the double-blind method, and then the result were compared.

\subsubsection{Questionnaire Method}

60 students in experimental classes got 60 parts of questionnaires and all 60 parts have been recovered, the recovery was $100 \%$. The tennis grading teaching has been recognized by students. The influence of tennis grading teaching on students' learning interest and attitude as first-hand information provided valuable information and evidence for this research.

\subsubsection{Mathematical Statistics Method}

This paper use mathematical statistical methods to handle a variety of experimental data and analyze the experimental results, then obtain the scientific evidence.

\section{The Results and Analysis of Research}

\subsection{Theoretical Basis for Grading Teaching Methods}

The so-called "grading teaching" is in the same type of option on physical education, Students will be divided into different levels of implementation of teaching classes according to different physical quality of sports ability, technology level, personality characteristics and accept ability of different students, and design different levels of teaching contents for different students, teaching objectives for teachers to choose according to actual situation using different organizational forms and teaching methods. The basic principle of hierarchical teaching is according to their aptitude. Distinction between teaching principles, according to the specific situation, the teaching guidance means analyzing the specific issues specific to the dialectical thought. Because, we are facing students different in the knowledge reserve, ability and aptitude, learning style, physical condition, the sports quality, technical level, personality characteristics, personal ambition. Students of this diversity will also require diversity teaching conditions and environment. Therefore, understanding the students' difference, provide suitable learning environment for students. According to the different students level, is the precondition for teachers to organize teaching activities, is also the necessary condition is to make every student get development. The traditional teacher-centered teaching mode is difficult to make the students as the main body of learning in the teaching process, and it is also difficult to make different types of students fully and comprehensive develop, and results to easy to have a "one size fits all" phenomenon. And of, one of the preparation program to adapt to the diversity of students and provide students with diverse learning conditions, is teaching according to students' individual differences. Make all kinds of students, respectively, get the best effect of learning at their own starting point, and make every student enjoy great education teaching methods. Hierarchical teaching, emphasizing the vary from person to person, object to make same model, same standard, organize a targeted group students for a series of teaching activities, thereby eliminating students' psychological pressure caused by differences in the levels of sports, so that the students can try their best in order to achieve their own training objective. Due to various levels of students between classes have the same goal, which is determined according to the students' ability and level so that the students in the same class have more easily and friendly teaching, cooperation and communication. Also, the relationships between the students are more harmonious, which is beneficial to form a free, harmonious and united classroom atmosphere, and exclude the 
interference of indifferent stimulus. Students in the activities will focus your attention on the things related to the goal, after the students completed the suitable level of task to get the higher goal, and make every student actively participate in teaching activities, and achieve the development of each student.

3.2Design and Experiment of Grading Teaching

3.2.1 The Design of Grading Teaching Method

(1) On the basis of understanding fully the basic situation of students, formulating teaching programs at all levels and curricula which including teaching objectives, teaching contents and evaluation criteria of tennis grading teaching. Taking into account the current situation of teachers and the site of teaching tennis, this grading adopt two levels, namely primary and advanced classes, and make their basic requirements, course content, teaching objectives, teaching organization. (Table 1)

\begin{tabular}{cl}
\multicolumn{2}{c}{ Table1 } \\
\hline Tennis Teaching Standards of primary and advanced classes \\
\hline Primary & $\begin{array}{l}\text { Students have interest in tennis and Students can master the basic } \\
\text { desire to improve, and physical fitness in } \\
\text { general. }\end{array}$
\end{tabular}
Advanced
Students have certain tennis basic or
Students can master fully the tennis
classes
have a good correlate sport technology, and physical fitness is better. technology, improve athletic skills and exercise skillfully, for lifetime.

(2) Mobilizing extensively and promoting actively, so that students have a comprehensive understanding on basic requirements, course content, teaching objectives and assessment standards of tennis classes teaching at all levels. To enable students have an objective evaluation to their own exercise ability, within the required time in each semester, students should conduct the special grade texts named "Sport ability level evaluation" organized by teachers, making it be an important basis for course-choosing. Students can contrast own ability based on the standards at all levels and combine with the suggestions professional teachers given when students choose courses, and then they analyze fully and choose their own classes objectively, to make sure they can get greatest benefit in learning.

(3) Based on the syllabus and studying textbook seriously, teachers should fully understand the actual situation of students at different levels. For different situation, they put forward different teaching requirements, design appropriate teaching methods, arrange different teaching organizations, highlighting their learning focus and do the preparatory work before class. So that students can be fully developed in their respective capacities and all types of students at same level class have a maximum level master in sports knowledge, technology and skills. Thereby best students can get a new level, students who have poor basis also can master the basic techniques and skills, improve physical fitness, and then build confidence and interest in sports.

(4) Handling issues at all levels of examination and evaluation in the hierarchical teaching. Exam should have obvious level differences and reflect different level, but also master the progress that different levels get in their learning, the appropriate achievements should obtain and reflect educational factors. It should avoid students choose primary classes for high scores or primary classes students get "discrimination" in the evaluation standard which would result in the phenomenon that students' enthusiasm was dampened. Exam is a very important part in the grading teaching, and the establishment of standards and methods is related directly to the grading teaching. At the same time, it should pay attention to the degree of difficulty being consistent in different courses at same level, and cannot lead to negative tendencies that students choose courses easily to pass because of the differences in text standards. 


\subsubsection{Teaching Experiment}

(1) 60 students in experimental classes, according to their own circumstances, declare primary classes or advanced classes. Based on this and organized the comprehensive testing of tennis basic technique and quality, then 60 students will eventually be divided into primary classes (30 students) and advanced classes (30 students) as their levels. Primary classes teach tennis basic technique while advanced classes focus on the tennis comprehensive technical education and improvement of sports skills. Specific embodiments conduct by the teaching plan and syllabus according to the grading teaching.

(2) 60 students in control classes, divided into two classes, still adopt the traditional teaching form, according to the original tennis teaching programs and syllabus.

(3) Experimental classes and the control classes have tennis lesson in the same conditions (space, equipment, hours, teachers, etc.) for a semester (2 hours per week).

(4) At the end of semester, experimental classes and control classes were mixed to texted and evaluated which adopted the double-blind method. Then the situations of tennis technique each student master have the technical standards and technical assessment text. Test group composed of five tennis professional teachers engaged in the tennis, they scored according to uniform standard. Specific methods were as follows: Subjects hit tennis five times in a row in the bottom line using the forehand and backhand technique technology tossed by the other and served five times in service area. The judges would give scores based on standards and technical completion of the technical subjects. Finally, the judge result would be tidied at each class, processed by statistical methods and then evaluated.

\subsection{The Analysis of Research}

After grading teaching experiment of tennis lesson for a semester, the results showed that the the three major technical scores of experimental classes were higher than the control classes in technical testing at end of the semester (Table 2). Statistical analysis showed the technical level of experimental classes and the control classes were significantly different, the learning technology experimental classes grasped was significantly better than the control classes. From the statistical point of their results distribution, the percentage of students in the experimental classes achieving excellent and good grades significantly higher than the control classes and score distribution biased in favor of high section. This shows that after the grade teaching reform, the teaching of experimental classes is better obviously than the traditional teaching of the control class.

Table 2 Three technical test scores of experimental classes and control classes

\begin{tabular}{lccccc}
\hline GRADE & $\mathrm{N}$ & FOREHAND & BACKHAND & SERVE POINTS & TOTAL SCORE \\
\hline $\begin{array}{l}\text { Experimental } \\
\text { classes }\end{array}$ & 60 & 89.1 & 85.6 & 68.9 & 81.2 \\
Control classes & 60 & 78.6 & 76.2 & 64.5 & 73.1 \\
Text & & $\mathrm{P}<0.05$ & $\mathrm{P}<0.05$ & $\mathrm{P}<0.05$ & $\mathrm{P}<0.05$ \\
\hline
\end{tabular}

From the effect of grading teaching which experimental classes adopt, it can be seen that in the PE optional classes, adopting hierarchical teaching methods purposefully would reflect the teaching principle of individualized instruction and differential measure. According to the comprehensive factors of students' athletic ability, hobbies and expertise, etc, making students have the grading teaching and so that they can achieve good results in the learning environment which enable them to adapt to their own level, ability and desire to meet. Grading teaching makes students in one class have similar level; it helps teachers to focus on. So that teachers are better able to select the appropriate teaching methods based on the actual situation of the students and better teach to make students improve greatly on the original basis. Traditional teaching does not consider grading problem, resulting in the students in a class have a large difference in the physical and technical level, and it's hard for teachers choose appropriate teaching methods in the preparation of lesson.

Since the grading teaching makes students' PE teaching goals closer to own actual situations, these goals are able to complete through their own efforts, thereby it can increase the students' 
self-confidence and enable students to experience the joy of success. When teaching goal is reached through own efforts, it will virtually generate a sense of accomplishment, these will stimulate students the desire to learn, improve students' interest in learning, and achieve optimization of teaching organization. From the survey results of experimental classes, $96 \%$ of the students in favor of teaching in the form of grading teaching. It can be seen that the vast majority of students support this teaching form, with a broad mass base. Therefore, whether from the effect of teaching itself or the educated their own feelings, they all indicate that adopt grading teaching method in college tennis optional course is feasible which has an important role to further improve the quality of teaching.

\section{Summary}

4.1 Grading teaching method meets with modern educational thought, the current situation and trend of reform of college sports, as well as the actual situation of current students' physical fitness, athletic ability and psychological characteristics. It has a significant effect on improving the quality of teaching.

4.2 Tennis grading teaching designs based on the principle of individualized instruction and differential measure. It is conducive to exert the teachers' leading role and the main role of students' learning. Putting forward the demands at different levels to students of different level and adopt different teaching methods, which can effectively improve students' learning self-confidence and interest in learning to make sure that each student gets a greater increase on the original basis.

4.3 Grading teaching make the sport skills of students in one class more similar, so that teachers can organize better teaching, choose effective teaching methods, organize teaching activities in a targeted manner and improve the effectiveness of teaching.

4.4 On the basis of understanding fully and mastering the situation of students, grading teaching should formulate syllabus and teaching plans in a targeted manner, and determine reasonably students' standards for selecting course. It makes grading work more accurate, reasonable and separates the layers, and then lay a good foundation for the grading teaching.

\section{References}

[1] The Ministry of Education, National College of Physical Education Curriculum Teaching Guidelines [R] , 2002, 8 .

[2] Jianguo Zhan, "Layered cooperative learning" in Hurdle Teaching Design and Application [J].Beijing Sport University Journal, 2004,(5):656 -658.

[3] Hui Ge, Xuefeng Xie, "Layered" Teaching Experimental Research of College Ping-Pong selective Course [J]. Wuhan Sport University Journal, 2004,(3):100 -102.

[4] Chuanyin Cheng, Zhihong Bao, Thinking About Curriculum Theory on College Sports Course Reform [J], Sports \& Science, 2004, (4): 75-77.

[5] Shaozeng Liu, Dengsong Zhou, New Physical Education [M], Beijing: Higher Education Press, 2004.

[6] Weide Shao, Physical education psychology [M], Beijing: Beijing Sports University Press, 2004. 